\title{
An Evaluation of Interactive Projections as Digital Enrichment for Orangutans
}

\begin{abstract}
Digital technologies are increasingly being incorporated into the provision of enrichment for captive primates, ranging from the ad-hoc use of iPads to specifically designed hardware installed in the design of new exhibits. In this article, we present a digital enrichment system that utilizes a novel approach with interactive projections, installed in the orangutan exhibit at Melbourne Zoo. While previous research into orangutan enrichment has involved reinforcement using food rewards, this study is the first investigation of digital enrichment for orangutans that does not involve food rewards. Rather, the interactive projections were designed to provide intrinsically rewarding environmental enrichment, instead of a cheaper or more variable way of delivering food. Our observations of orangutans' use of the system supports the approach of using interactive projections, finding that it is more responsive than capacitance or resistive based touch-screen technologies to the variety of ways that orangutans 'touch': with whole hands, feet, faces, and with objects. We also present the results from a preliminary study into the effect of this enrichment into orangutan behavior which found presence or use of the device did not affect time spent engaged in the majority of behaviors of the individuals studied.
\end{abstract}

\section{Authors}

Marcus Carter, The University of Sydney

Sally Sherwen, Zoos Victoria

Sarah Webber, The University of Melbourne

\section{Keywords}

Digital Enrichment, Kinect, Orangutan Welfare

This is the author manuscript accepted for publication and undergone full peer review but has not been through the copyediting, typesetting, pagination and proofreading process, which may lead to differences between this version and the Version of Record. Please cite this article as doi: 10.1002/zoo.21587.

This article is protected by copyright. All rights reserved. 


\section{Graphical Abstract}

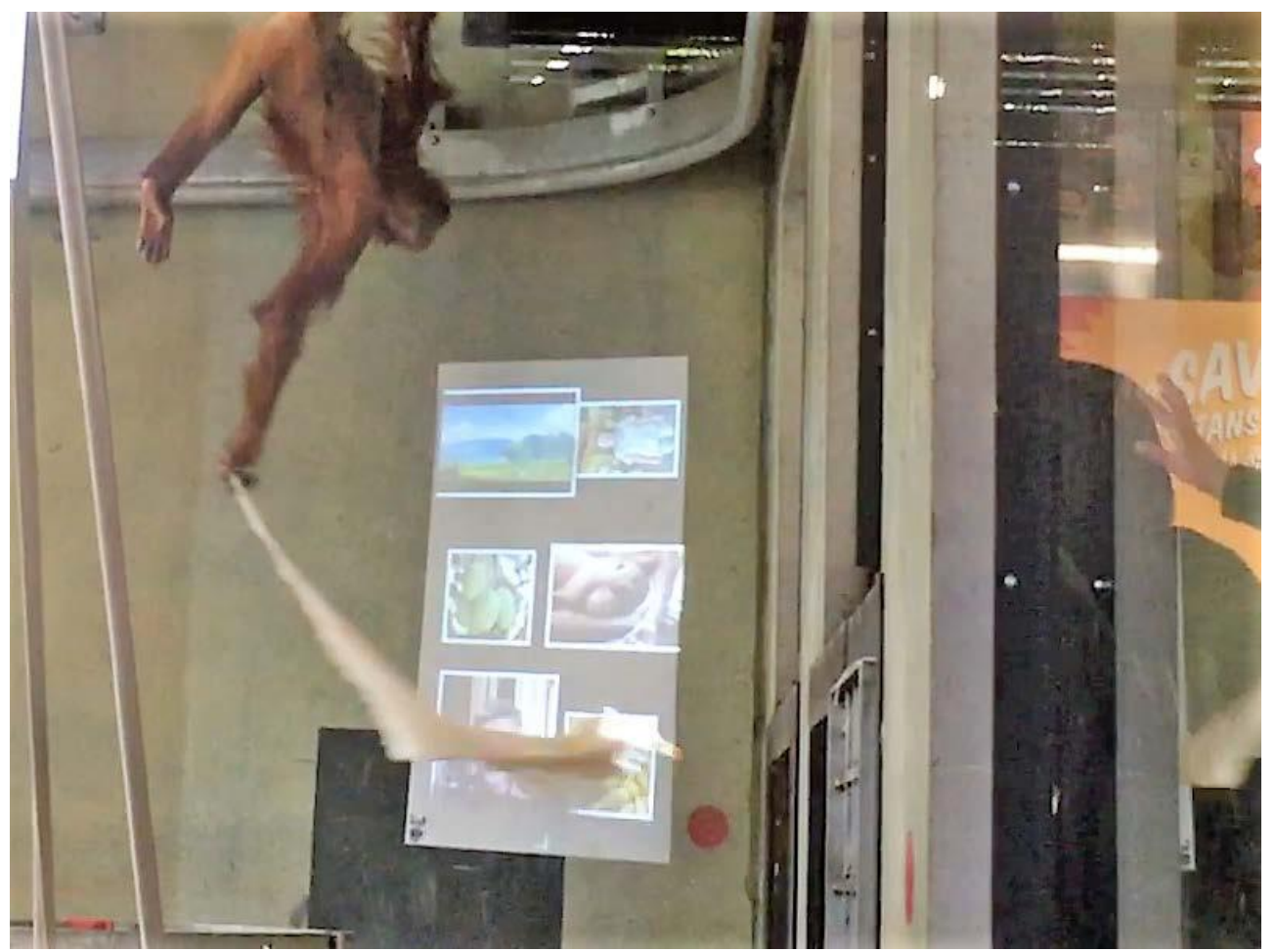

\section{Research Highlights}

Interactive projections provide a novel form of digital enrichment for Orangutans, not requiring the motivation of food rewards

\section{Introduction}

Digital technologies are increasingly being incorporated into the provision of enrichment for captive primates (Clay, Perdue, Gaalema, Dolins \& Bloomsmith 2011; Clark, Gray, Bennet, Mason \& Burgess 2019). Digital enrichment offers numerous benefits and opportunities alongside traditional forms of enrichment, such as being more flexible and customizable to individuals, not requiring the time of keepers, and providing an increased sense of control to captive animals (Carter, Webber \& Sherwen, 2015; Kim-McCormack, Smith \& Behie, 2016). Touch-enabled interfaces are one of the most common technologies used for this purpose, either by repurposing consumer technologies such as the iPad (e.g. see 'Apps for Apes'; Smith, 2011) or involving bespoke touch-screen technologies built into an enclosure (e.g. see Perdue, Clay, Gaalema, Maple \& Stoinski, 2012; Schmitt, 2018). Orangutans are a common target for these innovations and prior work has found that screen-based digital interfaces can be an effective form of enrichment for them (Tarou, Kuhar \& Bloomsmith, 2004; Perdue et al. 2012), and are increasingly used to conduct cognitive research (Schmitt, 2018; Egelkamp \& Ross, 2019). Further, both Perdue et al. (2012) and Webber et al. (2017) found that visitors respond positively to the presence of

This article is protected by copyright. All rights reserved. 
screen-based digital enrichment in orangutan enclosures, with Webber et al. (2017) arguing that on-display digital enrichment has the potential to improve the impact of conservation education and animal awareness.

Many instances of animals' reported use of screen-based digital enrichment across a wide variety of species - has involved reinforcement using food rewards (e.g., with orangutans see both Perdue et al. (2012) and Mallavarapu, Bloomsmith, Kuhar \& Taylor (2013)). In general, these examples of 'cognitive enrichment' are situated in research that has shown that animals may choose to work for their food even if the same food is freely available to them, a phenomenon called "contrafreeloading" (Inglis, Forkman \& Lazarus, 1997; Sasson-Yenor \& Powell, 2019; McGowan, Robbins, Alldredge \& Newberry, 2010; da Silva, Adania \& Ades, 2012). In contrast, the present study did not involve food rewards. In part, this was because we wanted to understand the breadth of ways orangutans might engage with and derive enrichment from the technology. It was felt that food rewards would reinforce specific interactions, limiting others, potentially skewing the results. In addition, following Clark (2011), we also note how a key opportunity for digital enrichment that has previously been overlooked is the opportunity that infinitely variable digital enrichment presents to provide intrinsically rewarding environmental enrichment, rather than just a cheaper or more variable way of delivering food.

Consumer digital technology is rarely sufficiently robust for use by great-apes, and re-appropriated applications designed for humans are also unlikely to be welldesigned for great-apes. In this project - a collaboration between human-computer interaction designers and animal welfare scientists - we developed a novel system that uses a standard video projector to project an interactive $1 \mathrm{~m} \times 0.7 \mathrm{~m}$ screen onto the wall, with touches detected by a Microsoft Kinect v2 depth sensor. The core objective of the present, preliminary, study was to investigate the effect of this alternate form of digital enrichment (in that it utilized an interactive projected image and did not involve food rewards) on specific indicators of positive welfare, such as greater activity and social play.

\section{Methods}

\section{Procedure}

\section{Animals and housing}

Five orangutans (three Sumatran and two hybrid Bornean-Sumatran) at Melbourne Zoo, Australia were given access to the digital enrichment over the period of this study: one adult male, three adult females, and one juvenile female (Table 1). All individuals were captive born. One sub-adult male did not participate in this study, but previously interacted with the enrichment and informed its iterative development. The orangutans were housed as two separate groups within the same sanctuary area of the zoo group 1) the adult male, one adult female and the juvenile

This article is protected by copyright. All rights reserved. 
female and group 2) the adult male (non-study participant) and two adult females (hybrid sp).

The orangutans were housed in a sanctuary exhibit consisting of three interconnected areas and a series of night dens. The digital enrichment was provided in a space referred to as the 'day-room', an indoor area $(8 \mathrm{~m}$ long $\mathrm{x} 4.7 \mathrm{~m}$ wide $\mathrm{x} 3.4 \mathrm{~m}$ high) with elevated platforms and climbing structures, with visitor windows along the side to allow viewing.

Animals were used to moving individually or with their group through the various areas of the sanctuary throughout the day as part of their standard husbandry routine to allow enrichment set up and servicing of the areas by keepers. This made shifting the individuals into the day room for their digital enrichment session part of their standard routine. With the only difference being access to the digital enrichment on treatment days.

\section{Table 1 - Summary of orangutan participants}

\begin{tabular}{|c|c|c|}
\hline Name & Sex & Age at Time of Study \\
\hline Santan & M & $40 \mathrm{yr}$ \\
\hline Mai & F & $31 \mathrm{yr} 5 \mathrm{~m}$ \\
\hline Dewi & F & $6 \mathrm{yr} 10 \mathrm{~m}$ \\
\hline Gabby & F & $27 \mathrm{yr} 9 \mathrm{~m}$ \\
\hline Kiani & F & $39 \mathrm{yr} 4 \mathrm{~m}$ \\
\hline
\end{tabular}

\section{Study design}

This study was designed to evaluate the effect of access to digital enrichment on individual orangutan behavior. Two treatments were studied;

1) Access to digital enrichment; Individual was given access to the day room for a one-hour period 10:45 - 11:45 and technology was enabled, and;

This article is protected by copyright. All rights reserved. 
2) Control; Individual was given access to the day room for one-hour period 10:45 - 11:45 but the technology was not enabled.

Treatments were randomly allocated to each individual over a total of 10 study days for each individual (5 days with technology enabled, 5 days without technology enabled). Except for the mother/juvenile pair, the orangutans only had individual access to the enrichment to reduce possibility of intra-group aggression over the new enrichment. The system rotated between each application every 2 minutes, unless the application was being used. On study days, animals underwent their normal husbandry routines and were allowed independent access to the day room for one hour in the morning (10:45-11:45), followed by access to the outdoor housing areas and their group mates for the afternoon. The only difference was that on treatment days, the digital enrichment device was enabled. Other standard enrichment was available in the day room on both treatment days and control days.

\section{Behavioral observations}

Observations were conducted by the same observer for the study period from the visitor area of the orangutan Sanctuary. During the 1-hour enrichment session in the day room (10:45-11:45), instantaneous sampling was used at 5-minute intervals to record the individuals' position in enclosure and behavioral state according to the ethogram below (see Table 2). In addition, continuous sampling was used to record all bouts of use of the Kinect system (which automatically recorded when it was being interacted with), allowing for finer analysis of the technology use. Engagements with the technology were scored 1-3, with 1 as observing the content but not touching, 2 as deliberate interaction, and 3 as significant interaction such as full-body or involving significant locomotion.

Following the one-hour observation period in the day room, the individual moved out to their outdoor housing areas and a further 2-hour observation period occurred (12;00 - 14:00) using the same instantaneous sampling protocol. This was designed to evaluate whether or not any changes in behavior occurred in the period following digital enrichment use.

Table 2 - Ethogram of orangutan Behaviors

\begin{tabular}{|l|l|l|}
\hline Behavior & Code & Description \\
\hline Standing erect & St & Bipedal or quadrapedal stance, head upright, stationary \\
\hline Sitting & S & Just sitting (no other action), head upright, stationary \\
\hline Lying & Ly & Recumbent with little or no weight on limbs, head lowered \\
\hline
\end{tabular}

This article is protected by copyright. All rights reserved. 


\begin{tabular}{|l|l|l|}
\hline Locomotion/climbing & Lo & Moving from one location to another walking, running or climbing \\
\hline Foraging & F & Manipulation of objects or substrate in an effort to obtain food \\
\hline Sitting eating & SE & Sitting and eating \\
\hline Allogrooming & A & $\begin{array}{l}\text { Direct touching using hands, teeth, or tongue or close visual } \\
\text { inspection of fur of another individual }\end{array}$ \\
\hline Sitting grooming & G & Sitting while grooming self \\
\hline Enrichment use & E & Interaction with enrichment (other than Kinect) \\
\hline Social Play & SP & $\begin{array}{l}\text { Nonaggressive interaction with another orangutan including } \\
\text { wrestling, rough and tumble play, chase play }\end{array}$ \\
\hline $\begin{array}{l}\text { Intragroup } \\
\text { aggression }\end{array}$ & Ag & $\begin{array}{l}\text { Directed at another individual, including facial threat, object shake, } \\
\text { or chase or contact including slapping, grabbing, biting or wrestling }\end{array}$ \\
\hline Pacing & P & $\begin{array}{l}\text { Repetitive, fast movement around top level of enclosure, often with } \\
\text { head-rolling part way through course. }\end{array}$ \\
\hline Out of view & Out of view \\
\hline
\end{tabular}

\section{Enrichment Design}

Our system utilized a Microsoft Kinect sensor and standard data projector to create a large 'touchscreen' style interface on the wall of the orangutan enclosure (see Figure 1). As existing software designed for human-use was not suitable for the orangutan exhibit as it either required human skeletal tracking (not possible over orangutan fur-hair) or physical sensors placed on the edges of the screen (destructible), we designed our own touch-detection software building on the approach of Wilson (2010), which was more responsive to the variety of ways that orangutans 'touch': with whole hands, feet, faces, and with objects. This system thus affords a larger interactive surface than would be achievable with a similarly priced touch-screen (in this case, $1 \mathrm{~m} \times 0.7 \mathrm{~m}$, with the potential to expand to a $2 \mathrm{~m} \times 1 \mathrm{~m}$ area) and permits a wider variety of ways of interacting than capacitance or resistive based touch-screen technologies.

This article is protected by copyright. All rights reserved. 


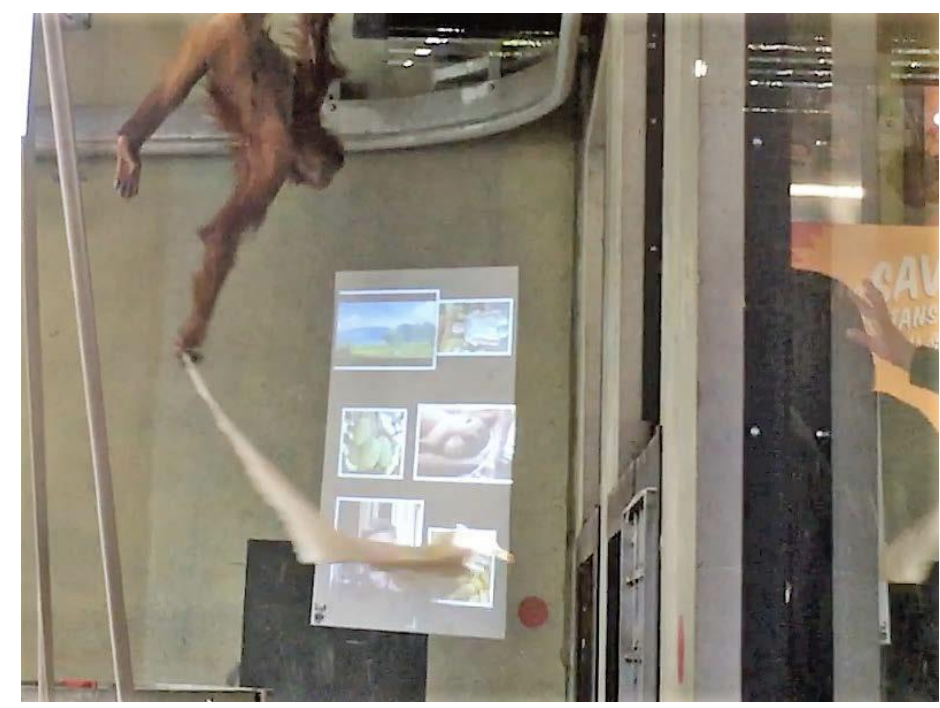

Figure 1: Juvenile female uses a sack to swipe at the Photos application

We adopted a user-centered design (UCD) process to explore how animalcomputer interaction (ACI) methods could contribute to the design of digital cognitive enrichment in the context of the zoo. Work like this in ACI seeks to explore how technology can utilized to reconfigure human-animal relationships "by allowing the animals' individual 'voice' to emerge" in the design process, as well as through use of the resulting technology (Mancini, Harris, Aengenheister \& Guest, 2015). We argue that UCD is an extremely appropriate design methodology for the Zoo, as UCD acknowledges that all design is embedded within wide social contexts, and there are a multitude of potential 'users', or beneficiaries, of a technology in the Zoo (such as visitors, zoo-keepers and animals). Our approach encompassed observations and interviews of visitors and keepers, along with extensive observations of the orangutans (drawing on Nippert-Eng (2015)), and design workshops with representatives of the different social contexts in the zoo. We developed 5 applications that were used in the study reported here: Burst, Sweep, Gallery, Painting and Match (described in Table 3). None of these applications involved food-rewards, and interactions with the system were not enticed or encouraged via food.

\section{Table 3 - Description of Games}

\begin{tabular}{l|l|l} 
Game & Description & Justification \\
\hline Burst & $\begin{array}{l}\text { Colored dots (approximately } \\
5 \mathrm{~cm} \text { ) that randomly moved } \\
\text { around the screen. When } \\
\text { touched they explode in a } \\
\text { burst of colorful light. }\end{array}$ & $\begin{array}{l}\text { Painted red dots were previously used in keeper } \\
\text { training sessions. As projections had previously } \\
\text { been used with these orangutans, we wanted an } \\
\text { immediately responsive interface so they } \\
\text { understood it was interactive, which also reflects } \\
\text { the advantages of digital enrichment to provide }\end{array}$
\end{tabular}

This article is protected by copyright. All rights reserved. 


\begin{tabular}{|c|c|c|}
\hline & & $\begin{array}{l}\text { immediate response and thus an added sense of } \\
\text { control (Kim-McCormack, 2016). }\end{array}$ \\
\hline Sweep & $\begin{array}{l}\text { Flashing red and blue tiles, } \\
\text { which disappear when } \\
\text { touched. }\end{array}$ & $\begin{array}{l}\text { As the other games require quite deliberate } \\
\text { action, Sweep was designed to allow and } \\
\text { encourage large hand and body interactions with } \\
\text { the interface. }\end{array}$ \\
\hline Gallery & $\begin{array}{l}\text { Photographs and videos (of } \\
\text { food, animals, orangutans, and } \\
\text { Zoo Keepers) are displayed in } \\
\text { a } 2 \times 3 \text { grid. When touched, a } \\
\text { photo is enlarged and occupies } \\
\text { the whole screen. A water- } \\
\text { ripple effect allows } \\
\text { interactions with the } \\
\text { photograph. }\end{array}$ & $\begin{array}{l}\text { Existing informal Keeper-use of screens with } \\
\text { these orangutans involved sharing and } \\
\text { displaying photos, which they show an interest } \\
\text { in. The goal of this application was to provide } \\
\text { the Orangutans with a choice of which photo to } \\
\text { view, similarly reflecting the opportunity of } \\
\text { digital enrichment to provide more control and } \\
\text { choice over their enrichment (Kim-McCormack, } \\
\text { 2016; Clark, 2011). }\end{array}$ \\
\hline Painting & $\begin{array}{l}\text { Touches to the screen (initially } \\
\text { white) leave colored marks. } \\
\text { Buttons (large circles of } \\
\text { different colors on screen } \\
\text { edge) change the color of the } \\
\text { marks. }\end{array}$ & $\begin{array}{l}\text { Painting was an existing non-digital enrichment } \\
\text { (requiring keeper-time). }\end{array}$ \\
\hline Match & $\begin{array}{l}\text { Touching/matching colored } \\
\text { shapes resulting in visually } \\
\text { engaging feedback (display of } \\
\text { a photo or video). Higher } \\
\text { levels present cognitive } \\
\text { challenge, requiring matching } \\
\text { by shape or color. }\end{array}$ & $\begin{array}{l}\text { Some orangutans had been taught to recognize } \\
\text { and match geometric shapes, using wooden } \\
\text { blocks, as a cognitive enrichment activity. The } \\
\text { goal of this application was to examine how a } \\
\text { digital system could be designed to present } \\
\text { cognitive tasks and reinforce correct responses } \\
\text { through non-food rewards. }\end{array}$ \\
\hline
\end{tabular}

\section{Statistical Analyses}

Not all behaviors listed in the ethogram (Table 2) were observed. To provide more meaningful behavioral summaries, we grouped some behaviors into broader categories including:

- $\quad$ Resting = sitting, lying, grooming or allogrooming

- Food-related $=$ foraging, sitting eating

- Active/play = locomotion, enrichment use (non-digital) and social play

- $\quad$ Alert $=$ standing erect

- $\quad$ Pacing $=$ pacing

For each individual orangutan, we calculated the average proportion of time (observation sample points) spent engaged in each observed behavior as listed above

This article is protected by copyright. All rights reserved. 
in each observation session to calculate an average proportion of time each individual spent engaged in each behavior on each study day.

An ANOVA was performed to investigate any treatment effects on each individual's behavior, using daily summary values for each behavior for each day as the units of analysis for each individual. SPSS version 24 was used. Significance was set at $\mathrm{p}<0.05$.

\section{Results}

Results are presented as a descriptive summary of total interactions with the technology by individual and across different applications, as well as a comparison between average time spent engaged in each behavioral category for each individual on days with access to digital enrichment and control days.

\section{Interactions}

The number of interactions with the system varied considerably between individual. The adult flanged male Santan and adult mother Mai only interacted with the system once during the study, which reflected their (lack of) interest in the system earlier in the process. The juvenile female, Dewi, interacted with it the most (6 interactions per session, 30 total interactions, 9 significant interactions, that is, those involving full-body interaction or significant locomotion). The two adult females also interacted with it between 2-3 times per session, see Table $4 \& 5$, but exhibited different application preference in doing so. Photographs, Sweep and Burst were the most interacted with application, but we note that Burst saw no prolonged interaction, see Table 5. The orangutans' interactions with the system declined over time. Initially, Dewi, Gabby and Kiani engaged in moderate levels of interaction. However, their use of the system waned over the course of the study. The observed interactions with the systems noted a wide range of ways that the orangutans interacted the system, from hanging and watching the screen at a distance, touching deliberately with hands, feet, and with fabric from both the floor and the ceiling, to examining the appearance of the projection on their bodies.

Table 4. Count of bouts of interactions with the technology system for each individual over all study days

\begin{tabular}{|c|c|c|c|c|}
\hline Orangutan & $\begin{array}{c}\text { (1) viewed } \\
\text { but not } \\
\text { touched }\end{array}$ & $\begin{array}{c}\text { (2) Deliberate } \\
\text { touches }\end{array}$ & $\begin{array}{c}\text { (3) Significant and } \\
\text { prolonged interaction }\end{array}$ & $\begin{array}{c}\text { Total } \\
\text { Interactions }\end{array}$ \\
\hline Santan & 1 & 0 & 0 & 1 \\
\hline
\end{tabular}

This article is protected by copyright. All rights reserved. 


\begin{tabular}{|c|c|c|c|c|}
\hline Mai & 1 & 0 & 0 & 1 \\
\hline Dewi & 4 & 17 & 9 & 30 \\
\hline Gabby & 2 & 6 & 2 & 10 \\
\hline Kiani & 7 & 5 & 3 & 15 \\
\hline
\end{tabular}

Table 5. Count of bouts of interactions with the technology system by Application from all individual orangutans over all study days

\begin{tabular}{|c|c|c|c|c|}
\hline Burst & 1 & 10 & 0 & 11 \\
\hline Photographs & 4 & 5 & 6 & 15 \\
\hline Painting & 2 & 2 & 2 & 6 \\
\hline Sweep & 3 & 8 & 3 & 14 \\
\hline TR & 0 & 3 & 2 & 5 \\
\hline Other & 2 & 2 & 2 & 6 \\
\hline
\end{tabular}

Behavioural time budget results

Access to the digital enrichment had no significant effect $(\mathrm{p}>0.05)$ on any individual orangutan's time spent engaged in resting, active/play, food-related or pacing (Fig 2). Access to digital enrichment resulted in an increase in Gabby's time spent alert (treatment mean 0.083, control mean 0.023, $\mathrm{p}=0.004$ ).

This article is protected by copyright. All rights reserved. 


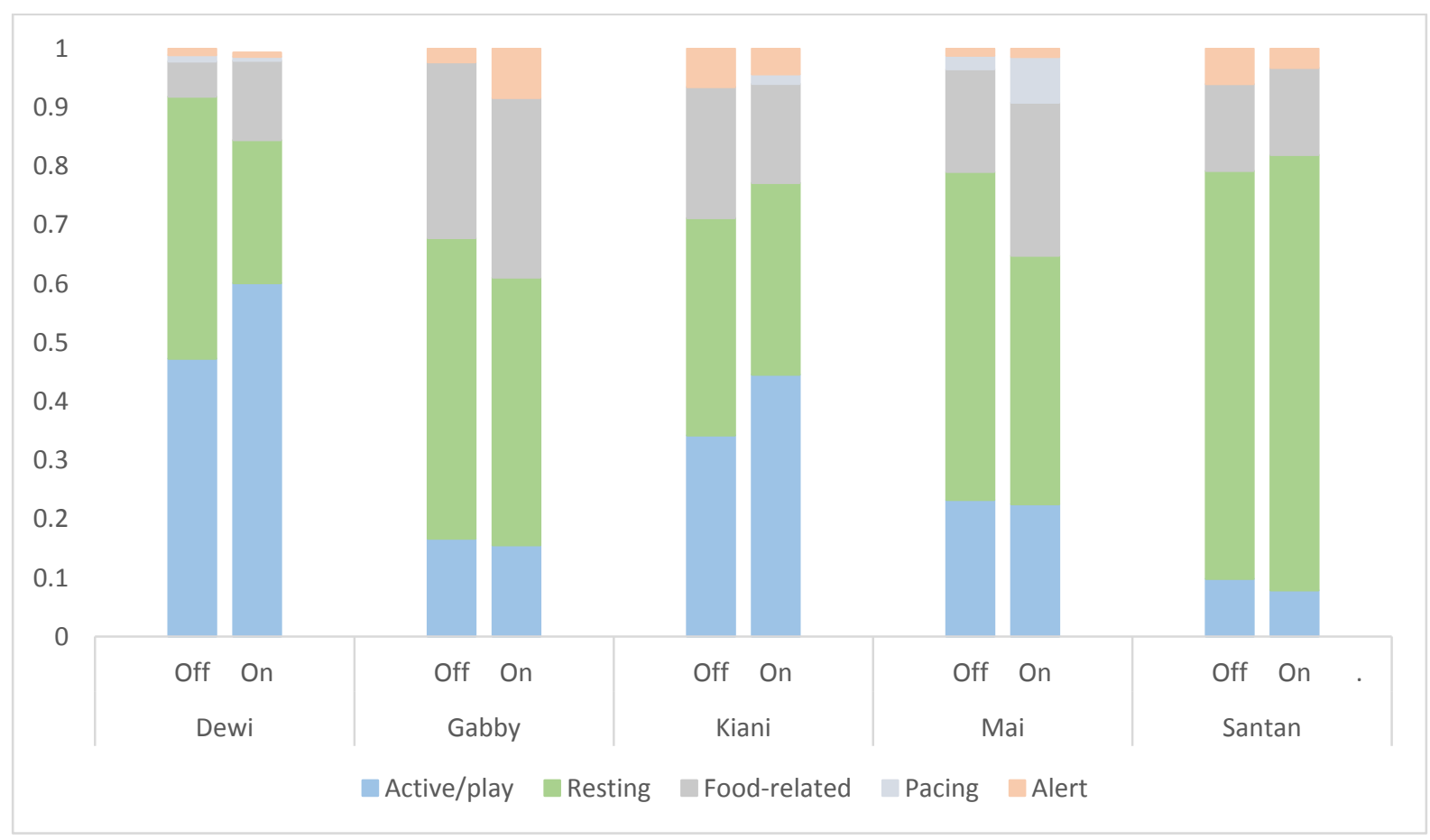

Figure 2. Summary of time spent engaged in each behavioral category for each individual on days with access to digital enrichment (on) and days without access to digital enrichment (off).

\section{Discussion}

The findings from this preliminary study suggest that digital enrichment in the form of interactive projections offered some form of interest or exploration opportunity for orangutans studied as we observed a variety of interactions with the enrichment in the absence of food reinforcement. However, presence or use of the device did not affect time spent engaged in the majority of behaviors of the individuals studied. This reflects work by Perdue et al. (2011) and Clark et al. (2019) who similarly found no negative or positive effects of such enrichment strategies. There was a trend towards an increased time spent engaged in all play behavior in Dewi and Kiani who were also the two individuals in the study with the highest number of bouts of interactions with the device and the highest number of bouts of prolonged interaction. The increased time spent engaged in alert behavior by Gabby, on days when the digital enrichment was enabled, may be a result of the novelty of the device however this behavior was observed at very low levels overall (less than $1 \%$ of time budget observed).

This study further found differences between individual orangutans, with the youngest interacting more than the adults. This similarly reflects findings in Perdue et al. (2012) who found high-use by a younger male orangutan and no use by the dominant adult male in the group, and Mallavarapu et al. (2013) who also found stark individual differences in digital enrichment use by orangutans. Taken together these

This article is protected by copyright. All rights reserved. 
differences in individual use may indicate that digital enrichment systems are more appropriate for younger orangutans. However, drawing conclusions across studies such as these is difficult considering the substantial differences in the nature of the digital enrichment, the design of the applications, and the limited observation duration. It is our hope that the flexible design of the digital enrichment system presented in this paper will allow for wider use in other enclosures, permitting broader insights into how, and for who, enrichment systems like these can be designed and employed.

A further point of difference for this enrichment design has been the lack of food reinforcement associated with use of the device, as employed in prior similar studies with orangutans (e.g. Perdue et al. 2011). In the current study, engagement with the digital enrichment (with a few exceptions) was typically ad-hoc and intermittent; rather than a focused activity as evidenced by the few interactions with the wall-based system that lasted more than 10 seconds. While food-based cognitive challenges such as puzzle feeders can engage orangutans in focused tasks for several minutes at a time, as Clark et al. (2019) note, "there has never been a duration or proportion of time proposed as an "acceptable" level of enrichment use" (p. 10-11). More general observations of orangutan behavior when engaging in foraging and nondigital play highlight how orangutan interactions with most sources of enrichment, (such as forage, objects and other orangutans), are similarly intermittent and of short duration. Thus, it should be expected that interactions without food stimuli, with games that are designed to support short bursts of interactions, should mirror these modes of interacting. In the context of the juvenile female Dewi, who utilized the system the most, it was observed that the digital enrichment became one of many sources of play within the enclosure that were similarly interacted with for multiple short periods of time. However, we note that when the same enrichment device was first configured on the floor (described in Webber et al. 2017), there were several very prolonged interactions (more than one minute, and up to ten in one case) by Gabby, Kiani and Dewi. These typically involved object-based interaction with the projection (such as collecting straw to play with under the projection or moving a hessian sack to hang above the projection to interact with it), or prolonged 'painting' sessions. This could be due to the location of the screen, but also due to the peak novelty when first installed on the floor.

The relatively short length of our study limits claims regarding the long-term enrichment potential of the applications we designed, although we do note that use of the system waned slightly over the course of the study. However, one of the advantages of digital enrichment is that it can be procedurally varied to maintain interest in the enrichment and promote exploratory behaviour (Mench, 1998). In the case of this study, the same five games were not altered during the observation period to provide consistency between individuals and across the study. We note that the keepers at Melbourne Zoo have continued to use the system intermittently with ongoing - but similarly infrequent - use by the orangutans. Since the capacity to vary

This article is protected by copyright. All rights reserved. 
the system by changing the nature of the games or introducing new games is one of the key advantages of digital enrichment, future work should consider longer-term studies and/or consider how constant variation in the games might impact orangutan use. Further, where individual differences in application use have been observed in this study (and in others involving food rewards, such as Perdue et al. (2012), Mallavarapu et al. (2013)) we argue that future work should also consider the nature and design of digital enrichment as being highly relevant. With a wider suite of games and applications, the personalization of digital enrichment to specific individual subjects may improve the possible benefit of these systems. Cross-institution collaboration investing in similar platforms would be an important step forward in developing a deeper understanding about individual versus species-specific differences in digital enrichment preference.

Robust digital platforms for animal-computer interaction also offer extensive opportunities for other forms of enrichment, which may be more suitable to individual orangutans. In particular we suggest interfaces such as the one described in this paper may be suitable for giving captive orangutans control and choice over environmental conditions (heating/cooling, lighting, visibility to guests), enclosure access (Owen, Swaisgood, Czekala \& Lindburg, 2005) enrichment (choice over food-based puzzles or intrinsic play, other enrichment activities) and in training, as a form of cognitive enrichment (Laule \& Desmond, 1998). As our system was added to an existing enclosure its size and affordances were restricted. Future enclosure designs should consider how digital enrichment systems can be embedded and replicated throughout the orangutan's captive environment.

This project involved a collaboration between researchers in animal welfare science and human-computer interaction (HCI), deploying a user-centered design approach to developing the enrichment platform and the specific applications that were used in this trial. This resulted in the use of a projection-based screen, rather than a tablet-PC type interface, which afforded a wider variety of ways of interacting which we observed. This included interacting with the screen with hands, feet and faces, as well as with objects such as blankets (in sweeping and whipping motions), plastic balls and straw. In the initial testing phases, orangutans seemed to be experimenting with the different ways that they could interact with the system, which we have elsewhere explored as a possible affordance for enrichment in the future (Pons, Carter \& Jaen, 2016). This supports the use of projection-based enrichment, which also affords the experience of seeing the projection on things (such as on the straw, or on the orangutans' body) as well as being interactive. Observations of these interactions were utilized in an iterative design process to improve the attraction of the interface to these orangutans. For example, in testing we increased the number of dots that would be displayed at once in Burst in response to sweeping and spinning behaviors, that indicated the orangutans were attracted to seeing more than one explosion at once (a more vivid and colorful reaction). The selection of photographs and videos in the Photos application were based on informal uses of digital photos by

This article is protected by copyright. All rights reserved. 
zoo keepers, but videos of the zoo-keepers themselves (following the suggestion by Hanna Wirman, who has previously explored the design of digital enrichment for orangutans (2013a, 2013b)) were the most popular. We note these observations here as Swaisgood and Shepherdson (2005) note that "if we are to gain a deeper understanding of which kinds of enrichment work best, we need to know exactly what was tried" (p. 515), and very limited prior work on digital enrichment with primates describes in detail the enrichment, and what is successful or not successful. These types of observations are useful for future work that seeks to replicate or build on studies, as zoos increasingly turn to digital technology to achieve the highest possible welfare standards for animals.

\section{Acknowledgements}

We would like to sincerely thank staff at Melbourne Zoo and Zoos Victoria for their support of this research project, in particular the primate keepers who generously facilitated and enabled the research.

This research was supported by funding from the Microsoft Research Centre for Social Natural User Interfaces, with technology development led by Zaher Joukhadar.

\section{Data Availability Statement}

The data that supports the findings of this study are available on request from the corresponding author. The data are not publicly available due to privacy or ethical restrictions.

\section{References}

Boostrom, H. (2013). Problem-Solving with orangutans (Pongo Pygmaeus and Pongo Abelii) and Chimpanzees (Pan Troglodytes): Using The iPad to Provide Novel Enrichment Opportunities. Master of Wildlife Science: Texas A\&M University.

Carter, M., Webber, S. \& Sherwen, S. (2015). Naturalism and ACI: Augmenting Zoo Enclosures with Digital Technology. In Proceedings of the $2^{\text {nd }}$ International Conference on Animal-Computer Interaction (ACI'15), 61-66. Iskandar, Malaysia.

Clark, F. E. (2011). Great ape cognition and captive care: Can cognitive challenges enhance well-being? Applied Animal Behaviour Science, 135(1), 1-12.

Clark, F. E., Gray, S.I., Bennett, P., Mason, L. J., Burgess, K. V. (2019). High-Tech and Tactile: Cognitive Enrichment for Zoo-Housed Gorillas. Frontiers in Psychology. 10, article 1574.

Clay, AW., Perdue, B.D., Gaalema, D.E., Dolins, F.L., Blomsmith, M.A. (2011). The use of technology to enhance zoological parks. Zoo Biology 30, 487-497.

da Silva Vasconcellos, A., Adania, C. H., \& Ades, C. (2012). Contrafreeloading in maned wolves: Implications for their management and welfare. Applied Animal Behaviour Science, 140(1-2), 85-91.

This article is protected by copyright. All rights reserved. 
Egelkamp, C. L., \& Ross, S. R. (2019). A review of zoo-based cognitive research using touchscreen interfaces. Zoo Biology, 38(2), 220-235.

Inglis, I. R., Forkman, B., \& Lazarus, J. (1997). Free food or earned food? A review and fuzzy model of contrafreeloading. Animal behaviour, 53(6), 1171-1191.

Kim-McCormack, N., Smith, C. Behie, A. (2016). Is interactive technology a relevant and effective enrichment for captive great apes? Applied Animal Behaviour Science 185, 1-8.

Laule, G., Desmond, T. (1998). Positive reinforcement training as an enrichment strategy. In D.J. Shepherdson, J.D. Mellen \& M. Hutchins (Eds.), Second nature: environmental enrichment for captive animals. (pp. 302-313). Washington, DC: Smithsonian Institution Press.

Mallavarapu, S., Bloomsmith, MA., Kuhar, CW., Taylor, ML. (2013). Using multiple joystick systems in computerised enrichment for captive orangutans. Animal Welfare 22(3), 401-409.

Mancini, C. (2011). Animal-computer Interaction: A Manifesto. Interactions 18(4), 69-73.

Mancini, C., Harris, R., Aengenheister, B., Guest, C. (2015). Re-Centering Multispecies Practices: A Canine Interface for Cancer Detection Dogs. In Proceedings of the ACM SIGCHI Conference on Computer Interaction (CHI'15), 2673-2682.

McGowan, R. T., Robbins, C. T., Alldredge, J. R., \& Newberry, R. C. (2010). Contrafreeloading in grizzly bears: implications for captive foraging enrichment. Zoo biology, 29(4), 484-502.

Mench J.A. (1998). Environmental enrichment and the importance of exploratory behavior. In D.J. Shepherdson, J.D. Mellen \& M. Hutchins (Eds.), Second nature: environmental enrichment for captive animals. (pp. 30-46).

Washington, DC: Smithsonian Institution Press.

Nippert-Eng, C.E. (2015). Watching Closely: A Guide to Ethnographic Observation. Oxford: Oxford University Press.

Owen, M. A., Swaisgood, R. R., Czekala, N. M., Lindburg, D. G. (2005). Enclosure Choice and Wellbeing in Giant Pandas: Is It All About Control? Zoo Biology 24, 475-481.

Perdue, BM., Clay, AW., Gaalema, D., Maple, TL., Stoinski, TS. (2012). Technology at the Zoo: The Influence of a Touchscreen Computer on orangutans and Zoo Visitors. Zoo Biology 31, 27-29.

Pons, P., Carter, M., \& Jaen, J. (2016). Sound to your objects: a novel design approach to evaluate orangutans' interest in sound-based stimuli. In Proceedings of the Third International Conference on Animal-Computer Interaction (ACI'16), 1-5.

Sasson- Yenor, J., \& Powell, D. M. (2019). Assessment of contrafreeloading preferences in giraffe (Giraffa camelopardalis). Zoo biology, 38(5), 414-423.

This article is protected by copyright. All rights reserved. 
Schmitt, V. (2018). Implementing new portable touchscreen-setups to enhance cognitive research and enrich zoo-housed animals. BioRxiv, 316042.

Smith, J. (2011, December 24). orangutans get appy. New Scientist, 212(2844/2845), 69-71.

Swaisgood, R., Shepherdson, D. (2005). Scientific Approaches to Enrichment and Stereotypies in Zoo Animals: What's been done and where should we go next? Zoo Biology 24, 499-518.

Tarou LR, Kuhar CW, Adcock D, Bloomsmith MA, Maple TL. (2004). Computerassisted enrichment for zoo-housed orangutans (Pongo pygmaeus). Animal Welfare 13, 445-453.

Webber, S., Carter, M., Sherwen, S., Smith, W., Joukhadar, J., Vetere, F. (2017). Kinecting with orangutans: Zoo Visitors' Empathetic Responses to Animals' Use of Interactive Technology. In Proceedings of the In Proceedings of the ACM SIGCHI Conference on Computer Interaction (CHI'17): 6075-6088.

Wilson, A. (2010). Using a Depth Camera as a Touch Sensor. In Proceedings of the ACM International Conference on Interactive Tabletops and Surfaces (ITS'10), 69-72.

Wirman, H. (2013a). orangutan play on and beyond a touchscreen in Cleland, K., Fisher, L. \& Harley, R. (Eds.) Proceedings of the 19th International Symposium of Electronic Art, ISEA2013, Sydney, 1-3, http://ses.library.usyd.edu.au/handle/2123/9475.

Wirman, H., (2013b). The playing Other and what we cannot help learning from the study of animal play. In Proceedings of the 2013 Digital Games Research Association Conference, (DIGRA'13). Atlanta, GA.

Wirman, H. (2014). Games for / with strangers - Captive orangutan (Pongo Pygmaeus) touch screen play. Antennae 30, 104-11.

This article is protected by copyright. All rights reserved. 


\section{University Library}

\section{- M M I E R R A A gateway to Melbourne's research publications}

Minerva Access is the Institutional Repository of The University of Melbourne

Author/s:

Carter, M;Sherwen, S;Webber, S

Title:

An evaluation of interactive projections as digital enrichment for orangutans

Date:

2021-01-27

Citation:

Carter, M., Sherwen, S. \& Webber, S. (2021). An evaluation of interactive projections as digital enrichment for orangutans. ZOO BIOLOGY, 40 (2), pp.107-114. https:// doi.org/10.1002/zoo.21587.

Persistent Link:

http://hdl.handle.net/11343/280737 